Aim of the study: To determine the cost-effectiveness of lung cancer (LC) screening with low-dose computerised tomography of the chest, as compared to an approach without screening, reimbursed today by the National Health Fund (NHF) in Poland.

Material and methods: In order to analyse the current costs of diagnostic and therapeutic procedures of a model LC patient treated today, a model group consisting of 199 consecutive patients diagnosed and treated in the Oncology Centre in Bydgoszcz, Poland from January 2007 to April 2010 was used. The number and type of performed procedures in this group was obtained from the Polish Register of Neoplasms and the NHF. Only direct medical costs were analysed. To calculate the total costs of screening, diagnostics, and treatment of the hypothetical LC patient who would have cancer diagnosed with screening $\mathrm{CT}$, data from the literature and costs calculated for the model group were used. Prices of procedures were obtained from the price list of the NHF on 30 April 2010 and did not change from that time until June 2014. Oneway sensitivity analysis was performed.

Results: The average cost per LC patient, diagnosed and treated without screening, is $5567.50 \mathrm{EUR}$, and median LC-specific survival is one year. In the hypothetical LC patient with cancer diagnosed by screening, the average cost is 13689.35 EUR per LC patient, with a median LC-specific survival of at least seven years. A calculated incremental cost-effectiveness ratio (ICER) is 1353.64 EUR/year of life gained.

Conclusions: Lung cancer screening with low-dose CT would be highly cost-effective in Poland.

Key words: lung cancer, low-dose CT, screening, cost-effectiveness analysis.

Contemp Oncol (Pozn) 2015; 19 (6): 480-486 DOI: $10.5114 /$ wo.2015.56656

\section{Cost-effectiveness analysis of lung cancer screening with low-dose computerised tomography of the chest in Poland}

\author{
Małgorzata Kanarkiewicz ${ }^{1}$, Tomasz J. Szczęsny ${ }^{2}$, Jerzy Krysiński ${ }^{1}$, \\ Adam Buciński ${ }^{3}$, Janusz Kowalewski ${ }^{2,4}$, Zbigniew Pawłowicz ${ }^{5}$
}

\author{
'Department of Pharmaceutical Technology, Nicolaus Copernicus University in Torun, \\ Collegium Medicum in Bydgoszcz, Bydgoszcz, Poland \\ 2Department of Thoracic Surgery, Oncology Center, Bydgoszcz, Poland \\ ${ }^{3}$ Department of Biopharmacy, Nicolaus Copernicus University in Torun, \\ Collegium Medicum in Bydgoszcz, Bydgoszcz, Poland \\ ${ }^{4}$ Department of Thoracic Surgery, Nicolaus Copernicus University in Torun, \\ Collegium Medicum in Bydgoszcz, Bydgoszcz, Poland \\ ${ }^{5}$ Managing Director of Oncology Center in Bydgoszcz, Poland
}

\section{Introduction}

Lung cancer is the most common neoplasm in the world. About 1.2 million new cases and 1.1 million deaths are recorded annually. In the last 60 years a 30 -fold increase in morbidity was noted [1, 2]. Median survival does not exceed one year. In Poland, stage I and II non-small cell lung cancer (NSCLC) is diagnosed in only $20 \%$ of patients, of whom only $3 / 4$ are operable [3-5]. More advanced stages have poor prognosis, despite expensive radiotherapy and chemotherapy. Early detection of lung cancer became possible with the introduction of chest computerised tomography (CT).

For the last twenty years, studies on lung cancer screening with low-dose chest CT have been conducted worldwide. The data obtained from these trials suggest that patients with LC detected by such screening have a high chance of cure. A high rate of stage I disease (50-100\%) as well as high resectability (80-100\%) are noted in these patients [6-8]. However, the results of cost-effectiveness analyses are equivocal $[9,10]$. Cost-effectiveness of screening varies in different countries because the rate of LC, rate of other pulmonary diseases, and costs of medical procedures differ. Therefore, we decided to calculate this cost-effectiveness for Poland.

The National Lung Screening Trial provided evidence of a $20 \%$ reduction in lung cancer mortality and a $6.7 \%$ decrease in all-cause mortality among current and former smokers at high risk [11]. As a result, the United States Preventive Services Task Force (USPSTF) has recommended this screening, allowing coverage of low-dose $\mathrm{CT}$ to private health insurers under provisions of the Affordable Care Act, which states that LDCT must be covered without cost-sharing by qualified health plans starting on 1 January 2015. Because private insurers cover medical expenses mostly for the population below 64 years of age while $70 \%$ of new lung cancer cases are diagnosed above that age, the decision of the Centres for Medicare \& Medicaid Services (CMS), which provides medical insurance for the elderly population, will be of key importance [12]. Following USPSTF recommendations, appropriate recommendations have been adopted by other organisations with an interest in LC, including the National Comprehensive Cancer Network, the American Association for Thoracic Surgery, the American College of Radiology, the Society of Thoracic Surgeons, the International Association for the Study of Lung Cancer, the American College of Chest Physicians, and the American Cancer 
Society [13]. This may trigger organisation of LC screening programs worldwide in the near future.

\section{Material and methods}

Costs and outcomes of single baseline low-dose chest CT screening versus no screening were compared. To calculate costs of diagnostics and treatment of LC without screening, a model group of 199 consecutive patients discharged in the year 2008 from the Department of Thoracic Surgery of the Oncology Centre in Bydgoszcz was used (ICD-10 code: C34). In the analysed group there were 47 women and 152 men. Their mean age was 64 years. A list of procedures that were reimbursed by the NHF in these 199 patients was obtained. This list contained procedures (ICD-9 codes), matched with diagnosis (ICD-10 codes), performed in these patients during the subsequent 40-month period, which allowed us to distinguish procedures performed due to LC and other diseases. Procedures reimbursed in the treatment of LC were divided into seven groups: 1) diagnosis and staging, 2) surgery, 3) chemotherapy, 4) radiotherapy, 5) palliative care, 6) small medical equipment and diapers, and 7) follow-up and treatment of complications and side-effects. A mean real cost was calculated for every group of procedures, according to the NHF pricelist published on 30 April 2010. Table 1 shows the costs of these procedures as paid by the NHF.

Statistical analysis was performed with STATISTICA 10 software package (StatSoft Inc., Tulsa, OK, USA). For all assessed parameters, mean and median values, first and third quartile, and 95\% confidence interval (CI) were calculated.

To make the model group representative for the entire population of LC patients in Poland, epidemiological data were obtained from several sources: annual reports of the national consultant in thoracic surgery and from the Polish Register of Neoplasms. Prices for medical procedures are the same all over the country, and they did not change from 2010 until June 2014.

To calculate costs of diagnostic procedures and treatment of LC detected with baseline low-dose CT screening, data were obtained from the literature and from the price list provided by the NHF. Discounting was not performed because the price list has not changed since the year 2010. Moreover, from the year 2010 to the year 2013 the difference between inflation and the discount rate obtained an average value of $1.05 \%$. We can assume that this difference is not relevant and argue that inflation is equal to the discount rate [14].

To calculate cost-effectiveness and ICER, LC-specific median survival, which was calculated since the day of diagnosis (in the screened population - minus the lead time), was used. Without screening the diagnosis is usually set up after onset of clinical manifestations, while in the screened group - after finding the tumour in chest CT. Median LC-specific survival was obtained from the literature. According to the literature, median survival of LC patients in Poland is about one year [15], and such median survival was assumed for further analysis.

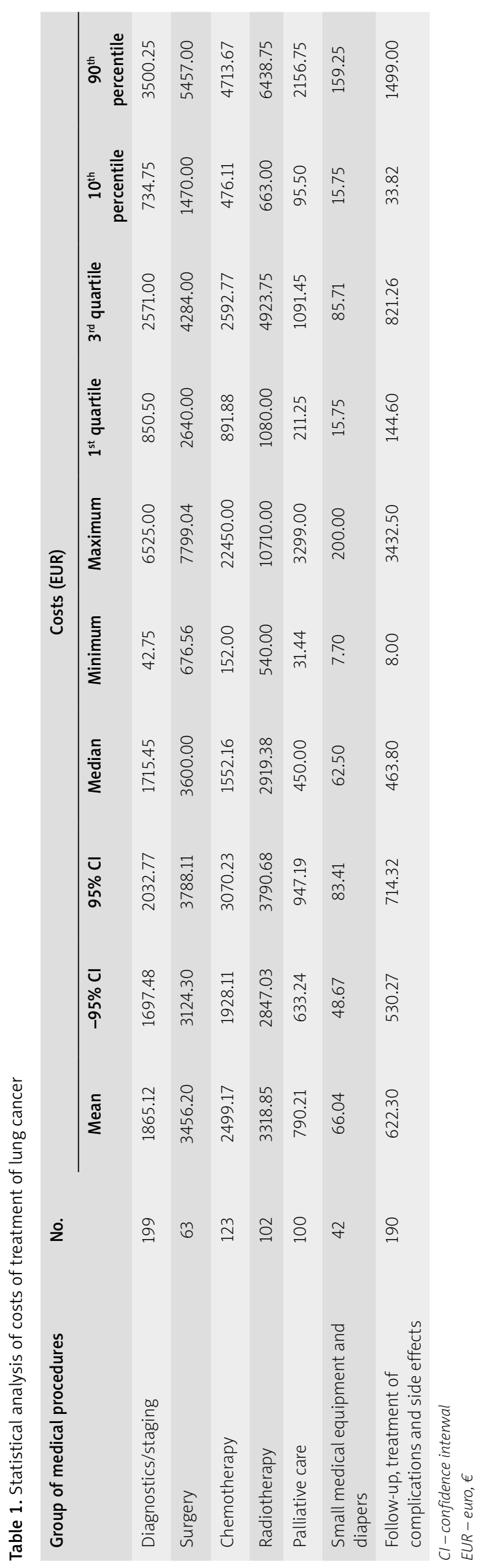


In the International Early Lung Cancer Action Project (I-ELCAP), the 10-year LC-specific survival was estimated for various subgroups of 484 participants who were diagnosed with LC, and the median 10-year survival rate was over $80 \%$ for the entire group $[6,16]$.

Median survival is the most commonly used parameter in the assessment of oncological treatment of lung cancer, which is a lethal disease for most involved patients. However, for the assessment of screening procedures, a lead time must be applied to the screening group. The lead time is the interval between diagnosis with the screening procedure and the onset of symptoms, which would otherwise allow diagnosis of the disease. The median survival of patients after screening should be reduced by the lead time [6].

Lead time was calculated using median values of tumour volume discovered by screening, compared with volume of tumour discovered after the onset of clinical symptoms, and on the basis of the doubling time of LC, which was obtained from the literature. Six doubling times are needed for the tumour to grow from $1000 \mathrm{~mm}^{3}$ (median volume of tumour diagnosed with screening [9]) to $64,000 \mathrm{~mm}^{3}$ (median volume of tumour diagnosed without screening - data obtained from the Oncology Centre in Bydgoszcz). Assuming that the doubling time of NSCLC is 180 days [9], the lead time is approximately three years (six doubling times). Therefore, for further analysis, the median survival of patients with cancer diagnosed by screening was calculated to be $10-3=7$ years.

In order to examine the impact of changes in key variables and assumptions on the results of the primary analysis, a sensitivity analysis was performed. Sensitivity analysis was used for costs of all groups of procedures.

\section{Results}

The median cost paid by the NHF for one LC patient diagnosed without screening is 5567.50 EUR (Table 2).

Table 2. Costs and outcomes of lung cancer discovered without and with screening

\begin{tabular}{|c|c|c|c|c|c|c|}
\hline \multirow[t]{2}{*}{ Group of procedures } & \multicolumn{3}{|c|}{ No screening } & \multicolumn{3}{|c|}{ Screening } \\
\hline & $\begin{array}{c}\% \text { of LC } \\
\text { patients } \\
\text { subjected to } \\
\text { the procedure }\end{array}$ & $\begin{array}{l}\text { Median cost } \\
\text { of procedures } \\
\text { from the } \\
\text { group (EUR) }\end{array}$ & $\begin{array}{l}\text { Median cost of } \\
\text { the procedure/ } \\
\text { LC patient (EUR) }\end{array}$ & $\begin{array}{c}\% \text { of LC } \\
\text { patients } \\
\text { subjected to } \\
\text { the procedure }\end{array}$ & $\begin{array}{l}\text { Median cost } \\
\text { of procedures } \\
\text { from the group } \\
\text { (EUR) }\end{array}$ & $\begin{array}{c}\text { Median } \\
\text { cost of the } \\
\text { procedure/LC } \\
\text { patient (EUR) }\end{array}$ \\
\hline $\begin{array}{l}\text { Screening with low-dose } \\
\text { chest } C T\end{array}$ & - & - & - & 100.00 & 50 & 50 \\
\hline Diagnostics and staging & 100.00 & 1865.12 & 1865.12 & 100.00 & 1298.25 & 1298.25 \\
\hline Surgery & 15.00 & 3456.20 & 518.43 & 76.76 & 3456.20 & 2652.98 \\
\hline Chemotherapy & 41.12 & 2499.17 & 1027.66 & 13.88 & 2499.17 & 346.88 \\
\hline Radiation therapy & 34.68 & 3318.85 & 1150.98 & 18.70 & 3318.85 & 620.62 \\
\hline Palliative care & 50.25 & 790.21 & 397.08 & 13.00 & 790.21 & 102.73 \\
\hline $\begin{array}{l}\text { Small medical } \\
\text { equipment and diapers }\end{array}$ & 21.10 & 66.04 & 13.93 & 5.50 & 66.04 & 3.63 \\
\hline $\begin{array}{l}\text { Follow-up, treatment of } \\
\text { complications and side } \\
\text { effects }\end{array}$ & 95.50 & 622.30 & 594.30 & $25.00 / 74.00$ & $622.30 / 694.50$ & 669.51 \\
\hline Median cost & & & 5567.50 & & & 5744.60 \\
\hline $\begin{array}{l}\text { Additional CT scans/LC } \\
\text { patient }\end{array}$ & & & - & & & 4050 \\
\hline $\begin{array}{l}\text { Additional diagnostics/ } \\
\text { LC patient }\end{array}$ & & & - & & & 3894.75 \\
\hline Total median cost & & & 5567.50 & & & 13689.35 \\
\hline Median survival (years) & & 1 & & & 7 & \\
\hline $\begin{array}{l}\text { ICER (EUR/year life } \\
\text { saved) }\end{array}$ & & & 135 & & & \\
\hline
\end{tabular}


Recently, in several countries, observational studies (without control group) were performed on chest CT screening in high-risk individuals. In Table 3 the results of selected studies are presented [9, 15-25]. Patient selection criteria differed between the analysed studies. The mean age of participants was 61.5 years. The presented data show the results of a single baseline screening.

The data presented in Table 3 show that LC is diagnosed in 1 out of 82 chest CT examinations. According to the International Early Lung Cancer Action Program (I-ELCAP) protocol, only solid lesions at least $15 \mathrm{~mm}$ in diameter were sent for immediate evaluation with the use a specialised computer program calculating nodule volume, according to the I-ELCAP decision tree [26]. We assumed that immediate evaluation would be needed for nodules at least 10 $\mathrm{mm}$ in diameter, but smaller lesions would be found in 1 out of 5 examinations. Data from the literature (Table 3) show that only 1 out of 4 lesions that require immediate control CT prove to be LC. Results of meta-analysis show that $96 \%$ of neoplasms diagnosed with low-dose chest CT (baseline screening) are non-small cell lung cancers (NSCLC), and only $4 \%$ are small-cell lung cancers (SCLC). According to data from the literature $[6,9,15,16,18,19]$ about $86 \%$ of NSCLC diagnosed with baseline screening are stage I disease (Table 3).

To calculate the cost of diagnostics and treatment of an average LC patient, it is necessary to calculate the percentage of patients who are subjected to procedures from the groups shown in Table 2. The percentage of patients who would receive surgical treatment, chemotherapy, or radiation for the treatment of SCLC and NSCLC was calculated using data from the literature $[6,9,16,27]$. Data concerning the percentage of patients subjected to other procedures (diagnostics and staging, palliative care, small medical equipment and diapers, follow-up, treatment of complications and side effects) were obtained from the model group of 199 patients.

In Table 2, median costs of diagnostics and treatment per LC patient diagnosed with low-dose chest CT screening that would have to be reimbursed by the NHF are presented.

The cost of diagnostics and staging procedures is calculated by summing the median cost of "diagnostics-and-staging procedures", one follow-up visit in the outpatient clinic, and the median cost of radiological and laboratory procedures (in candidates for radical treatment including positron emission tomography: $\mathrm{PET}(\mathrm{CT})$, giving 1298.25 EUR/patient. The median cost of diagnostics and staging of patients with cancer diagnosed with screening would therefore be lower than in patients with more advanced disease (1865.12 EUR, Table 2), because LC patients diagnosed with screening more often have early stage disease (86\% stage I NSCLC), which means that they do not need restaging due to recurrence or before the next step of multiple-approach treatment.

To calculate the median cost of treatment of LC patients diagnosed with screening, it was assumed that patients with operable stage IA and IB NSCLC do not have serious postoperative complications that increase the cost of treatment [28]. Treatment of early LC deserves a less invasive surgical approach and less extensive resections. Patients with an early LC (operable disease) do not have distant metastases, and do not require systemic treatment and palliative care. On the basis of this assumption, the percentage of patients who needed procedures from the last three groups of procedures listed in Table 2 was

Table 3. Results of single baseline screening with low-dose chest CT in asymptomatic smokers

\begin{tabular}{|c|c|c|c|c|c|c|}
\hline Institution, country & $\begin{array}{l}\text { Number of } \\
\text { participants }\end{array}$ & $\begin{array}{l}\text { Number (\%) of } \\
\text { positive results }\end{array}$ & $\begin{array}{l}\text { Number (\%) of } \\
\text { diagnosed LC }\end{array}$ & $\begin{array}{l}\text { NSCLC } \\
(\%)\end{array}$ & $\begin{array}{c}\text { Stage I } \\
\text { disease (\%) }\end{array}$ & $\begin{array}{l}\text { Mean age of } \\
\text { participants }\end{array}$ \\
\hline $\begin{array}{l}\text { Early Lung Cancer Action Project } \\
\text { (ELCAP), USA }[9,17]\end{array}$ & 1000 & $233(23)$ & $27(2.7)$ & 96 & 85 & 67 \\
\hline $\begin{array}{l}\text { New York Early Lung Cancer } \\
\text { Action Project (NY-ELCAP), US [18] }\end{array}$ & 6295 & $906(14)$ & $101(1.6)$ & 94 & 97 & 66 \\
\hline $\begin{array}{l}\text { International Early Lung Cancer } \\
\text { Action Project (I-ELCAP), US [16] }\end{array}$ & 31567 & $4186(13)$ & $405(1.3)$ & - & 86 & 61 \\
\hline Mayo Clinic, US [19-21] & 1520 & $782(51)$ & $30(2)$ & 93 & 75 & 59 \\
\hline $\begin{array}{l}\text { Anti-Lung Cancer Association } \\
\text { (ALCA), Japan [22] }\end{array}$ & 1611 & $186(12)$ & $13(0.8)$ & 100 & 77 & 60 \\
\hline $\begin{array}{l}\text { University of Munster, Germany } \\
{[23,24]}\end{array}$ & 817 & $350(43)$ & $11(1.3)$ & 91 & 70 & 53 \\
\hline $\begin{array}{l}\text { Pomeranian Pilot Program of Lung } \\
\text { Cancer Screening, Poland [15] }\end{array}$ & 2002 & $982(49)$ & $11(0.5)$ & 100 & 91 & 59 \\
\hline $\begin{array}{l}\text { The National Lung Cancer Trial, } \\
\text { US [25] }\end{array}$ & 26722 & $7191(27)$ & 270 & - & - & - \\
\hline Total & 71534 & $14816(21)$ & $868(1.2)$ & & & \\
\hline Median & 8942 & $1852(21)$ & 109 (1.2) & & & \\
\hline
\end{tabular}




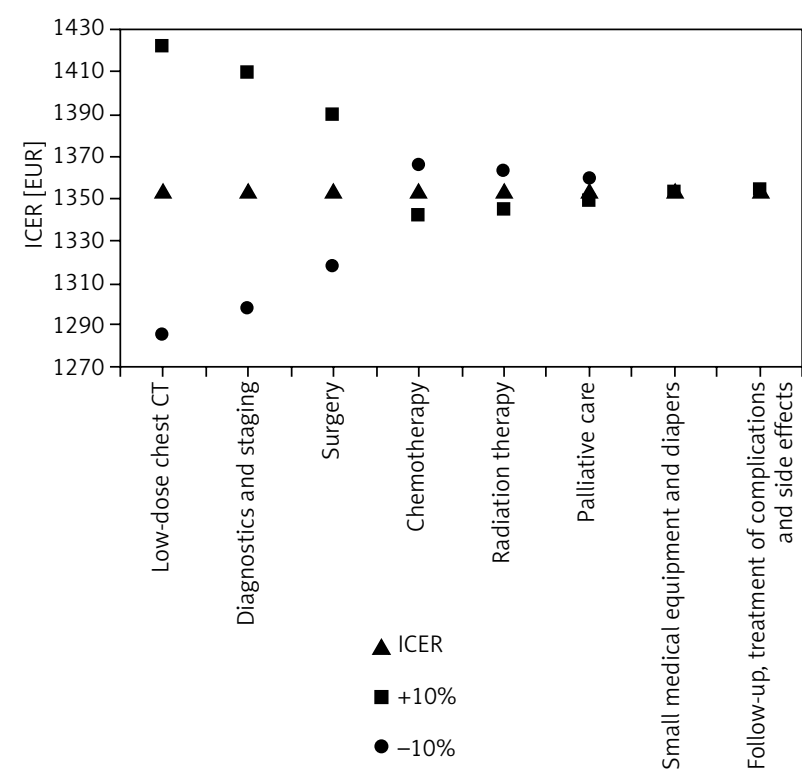

Fig. 1. The influence of changes of ICER for costs changes - baseline value for separate groups of procedures

calculated. Patients with operable stage IA and IB account for about $74 \%$ of all LC patients diagnosed with low-dose chest CT $[9,16]$. As a result of above-mentioned assumptions, procedures from the last three groups of procedures will be needed in $26 \%$ of patients in inoperable stages I through IV NSCLC, as well as in patients with SCLC. After extrapolation of costs of procedures from the model group of 199 patients into forecasted patients with LC diagnosed with screening, it can be assumed that cost of palliative care (13\% of patients) will be 102.73 EUR, and "small medical equipment and diapers" (5.5\% patients) will be 3.63 EUR. Procedures from the last group will be performed in $95.5 \%$ of patients with inoperable stages I through IV NSCLC and in most SCLC patients, which makes $25 \%$ of all patients with LC diagnosed with CT screening. Patients with curable (mostly by surgery) LC need follow-up visits. The total costs of follow-up visits in operable LC (74\% of LC diagnosed with screening) is 694.50 EUR, which includes:

- cost of 10 visits in an outpatient clinic - the average cost of one visit is 9.45 EUR,

- cost of 10 chest contrast CTs - the cost of one contrast chest CT is 60 EUR.

After summarising all costs from Table 2 for patients with LC diagnosed with screening, the total cost of diagnostics, treatment and follow-up of one LC patient would be 5744.60 EUR.

However, it must be remembered that LC is discovered in 1 out of 82 chest CTs in the high-risk group, and only one out of four non-calcified pulmonary nodules at least $5 \mathrm{~mm}$ in diameter will turn out to be LC. Patients with nodules larger than $10 \mathrm{~mm}$ in diameter or growing are sent for immediate diagnosis. Therefore, the NHF would have to reimburse also the cost of an additional 81 screening CTs (4050.00 EUR), as well as three diagnostics of pulmonary nodules (3894.75 EUR), which has to be added to the cost of diagnostics and treatment of LC discovered with screen- ing (5744.60 EUR). Altogether, it gives 13689.35 EUR, which is the total cost per LC patient diagnosed with screening.

The currently used approach to diagnose LC (without screening) yields one-year median survival with a cost of 5567.50 EUR per LC patient. According to published data, chest CT screening in high-risk individuals allows for at least 10 years median survival, which yields an addition to life span of seven years after administration of lead time. Despite the high cost of such an approach (13689.35 EUR per LC patient) the results of incremental analysis (ICER) show that the cost of a gained year of life for an LC patient with the use of chest CT screening is 1353.64 EUR.

The borderline cost-effectiveness of a medical procedure in Poland is set at three times the GDP (gross domestic product) per capita per one year of life gained. In the year 2014 three times the GDP was 27845.25 EUR [29], which makes the implementation of low-dose chest CT for screening of LC cost-effective.

To analyse the influence of changes of key variables and assumptions on the results of baseline analysis, single-factor sensitivity analysis was performed. Sensitivity analysis was used for costs of all groups of procedures. The influence of changes of variables on the above-mentioned costs was assessed for $\pm 10 \%$ baseline value (Fig. 1). The biggest impact on ICER changes was from costs of diagnostics and staging, and the cost of screening CT. In other groups of procedures, an increase or decrease of cost by $10 \%$ does not result in meaningful changes in the incremental cost and ICER value.

\section{Discussion}

Long-term results of treatment of LC depend on the stage of disease at diagnosis. Chest CT screening in the high-risk population (between 55 and 74 years of age at the time of randomisation, history of cigarette smoking of at least 30 pack-years, and, if former smokers, quitted within the previous 15 years) increases the cure rate in the screened population. A study performed in the US showed $20 \%$ mortality rate reduction in the screened arm and proved the positive impact of CT screening on the survival of high-risk individuals [25, 30].

Results of cost-effectiveness studies on screening for LC differ widely. Similar results as in our study were obtained by authors from Israel, where the cost per QALY (quality-adjusted life year) gained was \$1464 [31]. The analysis made on the basis of the results of the Early Lung Cancer Action Project (ELCAP) in the US indicates that screening for LC increases the overall survival in the highrisk population ( $\geq 60$ years old, who smoked at least 10 pack-years) by about 0.1 years. The incremental cost (difference between costs of two approaches) in the ELCAP study was $\$ 230$. The cost of one year of saved life (ICER) in this population was about $\$ 2500$. ICER equal to $\$ 2500$ is encouraging, and indicates that LC screening is highly cost-effective [9]. Cost-effectiveness analysis of the National Lung Screening Trial (NLST) performed in the US varies depending on the methods used. While some authors calculated that the additional cost of screening to avoid one LC death is $\$ 240,000$ [32], later calculations performed by a similar group of authors but after administra- 
tion of different methods found LC screening with LDCT to be highly cost-effective, with a cost per QALY gained of less than $\$ 19,000[18,33]$.

In the contrary, results of the analysis carried out in Australia show that ICER, depending on the age of highrisk individuals and number of pack-years smoked, ranges from 32617 Aus\$ to 114056 Aus\$ for one extra year of life [10].

In our study, costs and outcomes of LC screening detected with low-dose chest CT are compared with costs and outcomes when LC is detected and treated with the standard approach in Poland. The estimated average cost for diagnostics and treatment of an LC patient is currently 5567.50 EUR. It should be noted that this sum does not include the cost of outpatient visits in primary health care (PHC), emergency treatment, or the cost of reimbursed drugs, mainly painkillers, purchased in pharmacies on prescription. These additional costs can significantly influence the budget of the NHF. The study also does not include costs that are borne by patients, e.g. commuting to hospitals, absence from work, cost of labour of family members, etc.

The calculated average cost of diagnostic procedures and treatment of the patient, to be covered by the NHF, for LC detected with CT screening is 13689.35 EUR. This increased cost is due to the fact that LC is detected on average in 1 out of $82 \mathrm{CT}$ procedures. CT screening also results in the detection of multiple pulmonary nodules that are not LC. This increases the number of false positive results that require additional diagnostic tests and, consequently, increases the cost of screening. The cost of 81 chest CTs and additional diagnostic tests (PET CT, biopsy, contrast chest $\mathrm{CT}$, etc.) in patients who finally prove to be healthy, accounts for half of the costs.

The comparison of screening with no-screening shows that detection of LC with screening is both more effective and more expensive. The calculated ICER is 1353.64 EUR for one year of life gained. With the proposed limit of ICER in Poland equal to 24885.75 EUR it can be concluded that screening for LC is highly cost-effective. Results obtained on cost of screening in Poland are consistent with the results of Wisnivesky et al. and Manser, Dalton, and Carter et al. $[9,10]$.

Our study evaluated the cost-effectiveness of a single baseline CT scan. Mass screening programs are likely to consist of a baseline CT scan and, if the findings are negative, follow-up with annual repeat screenings for the following years. The incidence of LC is significantly lower on annual repeat screening, but the frequency of false positive findings also decreases [9]. Another weakness of our study is that we used median survival instead of life tables, which would be more accurate. Future research should be based on life tables, which is a more complex method.

An extra benefit of LC screening with low-dose CT is detection of other diseases in thorax and adjacent areas, for example in mediastinum, liver, suprarenals and kidneys. Chest CT also detects severe atheromatous changes in coronary arteries [15].
In conclusion: the cost of a single baseline lung cancer screening with low-dose chest CT plus the cost of treatment are almost twice as high as the cost of the current approach (without screening) but result in at least seven-times longer lung cancer-specific median survival.

The calculated ICER is 1353.64 EUR per one year of life gained.

Screening with single baseline low-dose chest CT for lung cancer in a high-risk population would be highly cost-effective in Poland.

The authors declare no conflict of interest.

\section{References}

1. Didkowska J. Epidemiologia i etiopatogeneza nowotworów płuca. In: Nowotwory płuca i opłucnej. Jassem J, Krzakowski M (eds.). Via Medica, Gdańsk 2009; 1-14

2. Yoder LH. Lung Cancer Epidemiology. Medsurg Nursing 2006; 15 : 171-5.

3. Potemski P. Rak płuca. In: Onkologia - podręcznik dla studentów i lekarzy (3rd ed.). Kordek R (eds.). Via Medica, Gdańsk 2007; 13646.

4. Rzyman W. Rak płuca. Forum Medycyny Rodzinnej 2008; 2: 407-19.

5. Kosacka M, Jankowska R. Epidemiologia raka płuca. Pneumonol Alergol Pol 2007; 75: 76-80.

6. Black WC. Computed Tomography Screening for Lung Cancer. Review of Screening Principles and Update on Current Status. Cancer 2007; 110: 2370-84.

7. Głogowski M. Badania przesiewowe w kierunku raka płuca. In: Nowotwory płuca i opłucnej. Jassem J, Krzakowski M (eds.). Via Medica, Gdańsk 2009; 19-23.

8. Patz EF, Swensen SJ, Herndon JE. Estimate of lung cancer mortality from low dose spiral computed tomography screening trials: implications for current mass screening recommendations. J Clin Oncol 2004; 22: 2202-6.

9. Wisnivesky JP, Mushlin Al, Sicherman N, Henschke C. The Cost-effectiveness of low-dose CT screening for lung cancer: preliminary results of baseline screening. Chest 2003; 124: 614-21.

10. Manser R, Dalton A, Carter R, Byrnes G, Elwood M, Campbell DA. Cost-effectiveness analysis of screening for lung cancer with low dose spiral CT (computed tomography) in the Australian setting. Lung Cancer 2005; 48: 171-85.

11. Aberle DR, Adams AM, Berg CD, et al. National Lung Screening Trial Research Team. Reduced lung-cancer mortality with lowdose computed tomographic screening. N Engl J Med 2011; 365: 395-409.

12. Wood DE.The Importance of lung cancer screening with low-dose computed tomography for medicare beneficiaries. JAMA Intern Med 2014; 174: 2016-8.

13. Pyenson BS, Henschke Cl, Yankelevitz DF, et al. Offering lung cancer screening to high-risk medicare beneficiaries saves lives and is cost-effective: an actuarial analysis. Am Health Drug Benefits 2014; 7: 272-82.

14. Central Statistical Office in Poland. Poland macroeconomic indicators. Annual macroeconomic indicators. Available from: http:// stat.gov.pl/wskazniki-makroekonomiczne/ [Accessed December 01, 2014].

15. Książek J, Dziedzic R, Jelitto-Górska M, Zakrzewska A, Serocka M, Biadacz I, Rzyman W. Pilot Pomeranian Lung Cancer Screening Program - preliminary report. Ann Acad Med Gedan 2009; 39: 73-82.

16. Henschke $\mathrm{Cl}$, Yankelevitz DF, Libby DM, Pasmantier MW, Smith JP, Miettinen OS, International Early Lung Cancer Action Program Investigators. Survival of patients with stage I lung cancer detected on CT screening. NEJM 2006; 355: 1763-71. 
17. Henschke Cl, McCauley DI, Yankelevitz DF, et al. Early Lung Cancer Action Project: overall design and findings from baseline screening. Lancet 1999; 354: 99-105.

18. New York Early Lung Cancer Action Project Investigators. CT screening for lung cancer: diagnoses resulting from the New York Early Lung Cancer Action Project. Radiology 2007; 243: 239-49.

19. Swensen SJ, Jett JA, et al. Screening for lung cancer with low-dose spiral computed tomography. Am J Respir Crit Care Med 2002; 165: 508-13

20. Swensen SJ, Jett JR, Hartman TE, et al. Lung cancer screening with CT: Mayo Clinic experience. Radiology 2003; 226: 756-61.

21. Swensen SJ, Jett JR, Hartman TE, et al. CT screening for lung cancer: five-year prospective experience. Radiology 2005; 235: 259-65.

22. Sobue T, Moriyama N, Kaneko M, et al. Screening for lung cancer with low-dose helical computed tomography: Anti-Lung Cancer Association project. J Clin Oncol 2002; 20: 911-20.

23. Diederich S, Wormanns D, Semik M, Thomas M, Lenzen H, Roos $\mathrm{N}$, Heindel W. Screening for early lung cancer with low-dose spiral CT: prevalence in 817 asymptomatic smokers. Radiology 2002; 222: 773-81.

24. Diederich S, Thomas M, Semik M, Lenzen H, Roos N, Weber A, Heindel W, Wormanns D. Screening for early lung cancer with low-dose spiral computed tomography: results of annual follow-up examinations in asymptomatic smokers. Eur Radiol 2004; 14: 691-702

25. The National Lung Screening Trial Research Team. Reduced Lung-Cancer Mortality with Low-Dose Computed Tomographic Screening. N Engl J Med 2011; 365: 395-409.

26. Pyenson BS, Henschke Cl, Yankelevitz DF, et al. Offering lung cancer screening to high-risk medicare beneficiaries saves lives and is cost-effective: an actuarial analysis. Am Health Drug Benefits 2014; 7: 272-82.

27. Mahadevia PJ, Fleisher LA, Frick KD, Eng J, Goodman SN, Powe NR. Lung cancer screening with helical computed tomography in older adult smokers: a decision and cost-effectiveness analysis. JAMA 2003; 289: 313-22.

28. Whitson BA, Groth SS, Duval SJ, Swanson SJ, Maddaus MA. Surgery for early-stage non-small cell lung cancer: a systematic review of the video-assisted thoracoscopicsurgery versus tho racotomy approaches to lobectomy. Ann Thorac Surg 2008; 86 2008-16.

29. Medical Technologies Assessment Agency. Announcement. Available from: http://www.aotm.gov.pl/www/index.php?id=779 [Ac cessed June 01, 2014]

30. Mountain CF. Revisions in the international system for staging lung cancer. Chest 1997; 111: 1710-7.

31. Shmueli A, Fraifeld S, Peretz T, Gutfeld O, Gips M, Sosna J, Shaham D. Cost-effectiveness of baseline low-dose computed tomography screening for lung cancer: the Israeli experience. Value Health 2013; 16: 922-31.

32. Goulart BH, Bensink ME, Mummy DG, Ramsey SD. Lung cance screening with low-dose computed tomography: costs, national expenditures, and cost-effectiveness. J Natl Compr Canc Netw 2012; 10: 267-75.

33. Pyenson BS, Sander MS, Jiang $Y$, et al. An actuarial analysis shows that offering lung cancer screening as an insurance ben efit would save lives at relatively low cost. Health Aff (Millwood) 2012; 31: 770-79.

\section{Address for correspondence}

\section{Małgorzata Kanarkiewicz}

Department of Pharmaceutical Technology

Collegium Medicum in Bydgoszcz

Jurasza 2

85-08 Bydgoszcz, Poland

e-mail:m.kanarkiewicz@cm.umk.pl

Submitted: 23.07 .2014

Accepted: 23.01.2015 